\title{
Preface
}

\section{Modern Critical Care \\ Endocrinology and Its Impact on Critical Care Medicine}

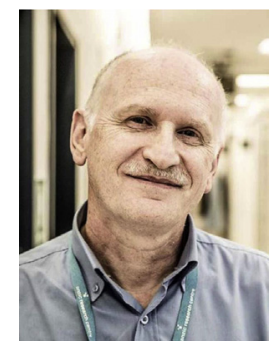

Rinaldo Bellomo, AO, MBBS (Hons), MD, PhD, FRACP, FCICM, FAAHMS Editor

Endocrinology and issues related to the role of hormones in critical care medicine remain a dominant component of physiologic investigations, pathophysiologic manipulation, and treatment in patients admitted to intensive care units (ICUs) worldwide. As an example, only in the last 12 months, three major multicenter phase 3 randomized controlled trials (RCTs) have been published, which involved the assessment of hormonal therapy (hydrocortisone and angiotensin II) in patients with septic shock. ${ }^{1-5}$

However, until now, there has not been any dedicated attempt to introduce critical care physicians to modern ideas and recent evidence in this rapidly evolving field. This issue of Critical Care Clinics aims to do just that, by taking clinicians into a critical care endocrinology world many would not be familiar with. Yet, this is a world that brings important new pathophysiologic insights and promising new therapies into the field. Such insights and therapies should already shape the practice of intensive care medicine and may well shape much of the future treatment of our patients.

For the purpose of this issue, we have specifically chosen aspects of critical care endocrinology that have seen major changes in our understanding of how specific hormones work, how disorders of hormonal function should be diagnosed, and how hormones should be used for therapy in the ICU. We have started from issues related to the inadequate and/or excessive antidiuretic hormone secretion (ADH), ${ }^{6}$ where modern endocrinology has delivered new diagnostic tools to our understanding of ADH (vasopressin) pathophysiology and where RCTs have provided new information about its use in septic shock ${ }^{7}$ and the possible beneficial renal effects of $A D H$ in this setting. We have then focused on emerging evidence for the possible role of hormone therapy in the management of trauma. ${ }^{8}$ However, the most dramatic new entrant in critical care endocrinology has been the arrival of angiotensin II therapy and its Food and Drug 
Administration approval as therapeutic agent after the completion and publication of the ATHOS-3 trial. ${ }^{9}$ Accordingly, two articles in this issue are dedicated to angiotensin II. One is focused on new insights into the physiology and pathophysiology of angiotensin II, angiotensin-converting enzyme (ACE) and ACE2, and the growing family of angiotensin hormones. ${ }^{10}$ The other is focused on its use for the treatment of vasodilatory shock. ${ }^{11}$ Given the approval of this agent for the treatment of refractory vasodilatory shock, such articles are mandatory reading for critical care physicians. Similarly, a reassessment of another treatment of septic vasodilatory shock comes from the ADRENAL and APROACCHSS trials, ${ }^{1,3}$ which together randomized more than 5000 patients with septic shock. In this issue, the primary investigators of the ADRENAL trial review the powerful evidence derived from such studies and highlight their implications for clinical practice. ${ }^{12}$

The interaction between hormonal therapy and trauma is further developed in an article dedicated to the therapeutic potential and RCT data regarding erythropoietin (EPO) therapy for trauma and traumatic brain injury, where strong biological data, RCT-derived data, and meta-analytical data show a clear signal that EPO treatment might increase survival in trauma patients. ${ }^{13}$

The management of hyperglycemia in critically ill patients has been a major field of investigation for almost two decades, with multiple studies and several major RCTs. However, the field is now focusing on diabetic patients as a unique group of critically ill patients where the lessons learned from undifferentiated cohorts of critically ill patients may not apply, especially when preadmission glycemia (assessed by HbA1 levels) has been poorly controlled. ${ }^{14,15}$ In this group of patients, permissive hyperglycemia may be both a rational approach and one capable of delivering significant benefits. ${ }^{15}$ This is especially true as new technologies of semicontinuous glucose monitoring are becoming available for diabetic patients. ${ }^{16}$ This controversial but rapidly evolving area is reviewed in a dedicated article. ${ }^{17}$ However, these are not the only changes sweeping through the world of diabetes management. Several large RCTs have now established the potential for novel oral hypoglycemic agents to modify the risk of major adverse clinical outcomes in patients with diabetes. In particular, two classes of agents have now become widely used as a result of such trials: the sodiumglucose 2 cotransporter inhibitors (so called "flozins") and the dipeptidyl peptidase-4 inhibitors (so-called "gliptins"). These new drugs and the evidence behind their use are presented in this issue, ${ }^{18}$ together with a review of a new class of hormones (the "incretins") $)^{19}$ that appear to have a powerful role in regulating glucose absorption and blood glucose concentration. ${ }^{20}$

Other areas of ICU endocrinology are rapidly expanding. The regulation of disturbed sleep and the prevention of delirium have become major priorities in the care of ICU patients. Accordingly, the use of melatonin and melatonin receptor agonists has grown and has attracted attention as a novel pharmacologic development in intensive care treatment. ${ }^{21}$

Novel insights into the regulation of iron movement in and out of cells and the role of iron as a catalyst for oxygen radical species generation have led to renewed interest in hormones that regulate its extracellular availability. Of these, hepcidin, the master regulator of iron fluxes, is the most important. It role in physiology and pathophysiology and the potential for its therapeutic effects are a crucial new development of great interest to ICU clinicians. ${ }^{22}$

Finally, studies on the role of thyroid hormones ${ }^{23}$ in the ICU, hormonal manipulation of organ donors, ${ }^{24}$ and hormonal manipulation to prevent post-ICU accelerated osteoporosis ${ }^{25}$ have markedly expanded our understanding of their pathophysiology and therapeutic potential. The implications of such new insights are reviewed in three key articles in this issue. 
In summary, critical care endocrinology is a fundamental area of intensive care practice and is rapidly expanding in its knowledge base and therapeutic implications. Critical care physicians have a unique opportunity to update their knowledge and understanding through this dedicated issue of Critical Care Clinics. I am sure they will find it stimulating, provocative, and with multiple implications for their clinical practice.

Rinaldo Bellomo, AO, MBBS (Hons), MD, PhD, FRACP, FCICM, FAAHMS
Department of Medicine
Radiology and Critical Care
Centre for Integrated Critical Care
The University of Melbourne
Melbourne, VIC 3084, Australia
E-mail address:
Rinaldo.bellomo@austin.org.au

\section{REFERENCES}

1. Venkatesh B, Finfer S, Cohen J, et al. Adjunctive glucocorticoid therapy in patients with sepsis shock. N Engl J Med 2018;378:797-808.

2. Billot L, Venkatesh B, Myburgh J, et al. Statistical analysis plan for the adjunctive corticosteroid treatment in critically ill patients with septic shock (ADRENAL) trial. Crit Care Resusc 2017;19:183-91.

3. Annane D, Renault A, Brun-Buisson B, et al. Hydrocortisone plus fludrocortisone for adults with septic shock. N Engl J Med 2018;378:809-18.

4. Bellomo R, Hilton A. The ATHOS-3 trial, angiotensin II and the three musketeers. Crit Care Resusc 2017;19:1-4.

5. Chawla LS, Russell JA, Bagsahw SM, et al. Angiotensin II for the treatment of high-output shock 3 (ATHOS-3): protocol for a phase II, double-blind, randomised controlled trial. Crit Care Resusc 2017;19:43-9.

6. Harrois A, Anstey JR. Diabetes insipidus and syndrome of inappropriate antidiuretic hormone in critically ill patients. Crit Care Clin 2019;35(2):187-200.

7. Ukor IF, Walley KR. Vasopressin in vasodilatory shock. Crit Care Clin 2019;35(2): 247-61.

8. Asehnoune K, Vourch'h M, Roquilly A. Hormone therapy in trauma patients. Crit Care Clin 2019;35(2):201-11.

9. Khanna A, English SW, Wang XS, et al. Angiotensin II for the treatment of vasodilatory shock. N Engl J Med 2017;377:419-30.

10. Bitker L, Burrell LM. Classic and nonclassic renin-angiotensin systems in the critically ill. Crit Care Clin 2019;35(2):213-27.

11. Wakefield BJ, Busse LW, Khanna AK. Angiotensin II in vasodilatory shock. Crit Care Clin 2019;35(2):229-45.

12. Venkatesh B, Cohen J. Hydrocortisone in vasodilatory shock. Crit Care Clin 2019; 35(2):263-75.

13. French C. Erythropoietin in critical illness and trauma. Crit Care Clin 2019;35(2): 277-87.

14. Plummer MP, Finnis ME, Horsfall M, et al. Prior exposure to hyperglycemia attenuates the relationship between glycaemic variability during critical illness and mortality. Crit Care Resusc 2016;18:189-97.

15. Martensson J, Bailey M, Venkatesh B, et al. Intensity of early correction of hyperglycemia and outcome of critically ill patients with diabetic ketoacidosis. Crit Care Resusc 2017;19:266-73. 
16. Ancona P, Eastwood G, Lucchetta L, et al. The performance of flash glucose monitoring in critically ill patients with diabetes. Crit Care Resusc 2016;18: 167-74.

17. Balintescu A, Mårtensson J. Hemoglobin A1c and permissive hyperglycemia in patients in the intensive care unit with diabetes. Crit Care Clin 2019;35(2): 289-300.

18. Libianto R, Ekinci El. New agents for the treatment of type 2 diabetes. Crit Care Clin 2019;35(2):315-28.

19. Plummer MP, Hermanides J, Deane AM. Incretin physiology and pharmacology in the intensive care unit. Crit Care Clin 2019;35(2):341-55.

20. Miller A, Deane AM, Plummer MP, et al. Exogenous glucagon-like peptide-1 attenuates glucose absorption and reduces blood glucose concentration after small intestinal glucose delivery in critical illness. Crit Care Resusc 2016;19: 37-42.

21. Marra A, McGrane TJ, Henson CP, et al. Melatonin in critical care. Crit Care Clin 2019;35(2):329-40.

22. Chawla LS, Beers-Mulroy B, Tidmarsh GF. Therapeutic opportunities for hepcidin in acute care medicine. Crit Care Clin 2019;35(2):357-74.

23. Maiden MJ, Torpy DJ. Thyroid hormones in critical illness. Crit Care Clin 2019; 35(2):375-88.

24. Opdam HI. Hormonal therapy in organ donors. Crit Care Clin 2019;35(2): 389-405.

25. Orford NR, Pasco JA, Kotowicz MA. Osteoporosis in the critically ill patient. Crit Care Clin 2019;35(2):301-13. 